\title{
Anti-Inflammatory Effect of Recreational Exercise in TNBS-Induced Colitis in Rats: Role of NOS/HO/MPO System
}

\author{
Zita Szalai, ${ }^{1}$ András Szász, ${ }^{2,3}$ István Nagy, ${ }^{3}$ László G. Puskás, ${ }^{4,5}$ \\ Krisztina Kupai, ${ }^{1}$ Adél Király, ${ }^{1}$ Anikó Magyariné Berkó, ${ }^{1}$ Anikó Pósa, ${ }^{1}$ \\ Gerda Strifler, ${ }^{3}$ Zoltán Baráth, ${ }^{8}$ Lajos I. Nagy, ${ }^{4}$ Renáta Szabó, ${ }^{1}$ Imre Pávó, ${ }^{1}$ \\ Zsolt Murlasits, ${ }^{6}$ Mariann Gyöngyösi, ${ }^{7}$ and Csaba Varga ${ }^{1}$ \\ ${ }^{1}$ Department of Physiology, Anatomy and Neuroscience, University of Szeged, Közép Fasor 52, Szeged 6726, Hungary \\ ${ }^{2}$ Institute of Physical Education and Sport Sciences, University of Szeged, Szeged 6725, Hungary \\ ${ }^{3}$ Institute of Biochemistry, Biological Research Centre of the Hungarian Academy of Sciences, Szeged 6726, Hungary \\ ${ }^{4}$ AVIDIN Ltd., Szeged 6726, Hungary \\ ${ }^{5}$ Institute of Genetics, Biological Research Center of the Hungarian Academy of Sciences, Szeged 6726, Hungary \\ ${ }^{6}$ Semmelweis University, Faculty of Physical Education and Sport Sciences, Budapest 1123, Hungary \\ ${ }^{7}$ Department of Cardiology, Medical University of Vienna, 1090 Wien, Austria \\ ${ }^{8}$ University of Szeged, Faculty of Dentistry and Department of Orthodontics and Pediatric Dentistry, Szeged 6720, Hungary
}

Correspondence should be addressed to Csaba Varga; vacs@bio.u-szeged.hu

Received 26 June 2013; Revised 10 December 2013; Accepted 12 December 2013; Published 6 February 2014

Academic Editor: Pedro Tauler Riera

Copyright (C) 2014 Zita Szalai et al. This is an open access article distributed under the Creative Commons Attribution License, which permits unrestricted use, distribution, and reproduction in any medium, provided the original work is properly cited.

There are opposite views in the available literature: Whether physical exercise has a protective effect or not on the onset of inflammatory bowel disease (IBD). Therefore, we investigated the effects of recreational physical exercise before the induction of colitis. After 6 weeks of voluntary physical activity (running wheel), male Wistar rats were treated with TNBS (10 mg). $72 \mathrm{hrs}$ after trinitrobenzene sulphonic acid (TNBS) challenge we measured colonic gene (TNF- $\alpha$, IL-1 $\beta$, CXCL1 and IL-10) and protein (TNF- $\alpha$ ) expressions of various inflammatory mediators and enzyme activities of heme oxygenase (HO), nitric oxide synthase (NOS), and myeloperoxidase (MPO) enzymes. Wheel running significantly increased the activities of HO, constitutive NOS (cNOS) isoform. Furthermore, 6 weeks of running significantly decreased TNBS-induced inflammatory markers, including extent of lesions, severity of mucosal damage, and gene expression of IL-1 $\beta$, CXCL1, and MPO activity, while IL-10 gene expression and cNOS activity were increased. iNOS activity decreased and the activity of $\mathrm{HO}$ enzyme increased, but not significantly, compared to the sedentary TNBS-treated group. In conclusion, recreational physical exercise can play an anti-inflammatory role by downregulating the gene expression of proinflammatory mediators, inducing anti-inflammatory mediators, and modulating the activities of $\mathrm{HO}$ and NOS enzymes in a rat model of colitis.

\section{Introduction}

Inflammatory bowel disease (IBD) is a chronic disease of the gastrointestinal tract, which primarily comprises Crohn's disease (CD) and ulcerative colitis. Physical exercise can be either harmful or beneficial for the gastrointestinal (GI) tract depending on the training variables, such as exercise intensity. For instance, it is believed that the reduced blood flow to the gut during exercise can disturb the GI system [1].
Although there are similar studies suggesting the preventive effect of active lifestyle on the onset of IBD, the available literature is weak and contradictory $[2,3]$.

In the healthy gut interleukin-10 (IL-10) is the key cytokine responsible for the anti-inflammatory environment, primarily through the suppression of proinflammatory cytokines [4]. Once the anti- and proinflammatory balance of the intestinal immune system is disturbed, the activated and stimulated macrophages and $\mathrm{T}$ lymphocytes release 
proinflammatory mediators such as tumour necrosis factor$\alpha$ (TNF- $\alpha)$, interleukin- $\beta$ (IL- $1 \beta)$, and chemokine ligand 1 (CXCL1). The importance of anti- and proinflammatory balance is reflected in the efficacy of anti-TNF- $\alpha$ therapy in the treatment of IBD [5]: TNF- $\alpha$ inhibitors have proven successful in inducing and maintaining remission of moderateto-severe IBD. In addition, CXCL1 is a chemoattractant for neutrophils and plays a role in inflammation; increased ileal and colonic CXCL1 gene expression was also reported in IBD patients [6].

IBD is associated with enhanced production of reactive metabolites of oxygen and nitrogen (RONS). Moreover, oxidative stress plays an important role in the pathogenesis of this disease [7]. Heme oxygenase-1 (HO-1), the inducible isoform of heme oxygenase enzymes, is a stressresponsive enzyme, which can be induced by oxidative stress, inflammatory cytokines, and many other molecules. HO1 is thought to play an important role in the protection of tissues from oxidative injuries and inflammation [8-10]. These beneficial effects of HO-1 are mediated in part by the antioxidant and anti-inflammatory end products of heme breakdown, namely, $\mathrm{CO}$ and bilirubin, which can inhibit the expression of proinflammatory cytokines, such as TNF$\alpha$ and IL-1 $\beta$. Several molecules, such as interleukin-10 (IL10) function through an HO-1 dependent mechanism $[11,12]$. Pharmacological studies suggest a beneficial role for $\mathrm{HO}-1$ in modulating colitis. Upregulation of HO-1 by heme and cadmium chloride can ameliorate while inhibition of the enzyme by tin protoporphyrin can aggravate experimental inflammation in the colon [13]. 5-Aminosalicylic-acid, a clinically approved anticolitic agent, can exert beneficial effects in vivo, partially through the induction or activation of HO-1 [14].

Another enzyme involved in intestinal inflammation and oxidative stress is nitric oxide synthase [15]. The constitutive production of NO derived from the constitutive isoforms of the enzyme, namely, neuronal NOS (nNOS) and endothelial NOS (eNOS), plays a role in various physiological processes in the GI mucosa, such as the regulation of microvascular and epithelial permeability and the maintenance of adequate perfusion [16]. On the other hand the effects of iNOSproduced [15] NO can be beneficial or detrimental depending on the amount, duration, and anatomical site of synthesis $[16,17]$. In experimental colitis the downregulation of $\mathrm{nNOS}$ and the overproduction of NO by iNOS are observed [18]. For example, proinflammatory cytokines, such as TNF- $\alpha$, can induce NO production and iNOS activity in colonic epithelial cells [17].

Earlier studies have focused mainly on the role of exercise in the treatment of extraintestinal manifestations of IBD [19, 20]. However, the effects of physical exercise on the inflamed gut are still inconsistent. Therefore, the aims of the present study were to investigate the effects of recreational physical exercise (1) on the colonic damage in a TNBS rat model (damage score, lesion), (2) on the gene expression (TNF- $\alpha$, IL-1 $\beta$, CXCL1, and IL-10) and protein concentration (TNF- $\alpha$ ) of inflammatory mediators in experimental acute colitis, and (3) on the activity of oxidative/antioxidative enzymes (MPO, $\mathrm{HO}$, and NOS) in the inflamed colon of rats. We hypothesized that voluntary exercise prior to TNBS challenge will reduce colonic damage and oxidative and inflammatory mediator gene and protein expressions.

\section{Materials and Methods}

2.1. Animals. Male Wistar rats (180-220 g) were housed in groups. Food was withdrawn overnight before induction of colitis; otherwise, the animals had access to food and drinking water ad libitum throughout the experiments. The animal care and research protocols were in accordance with the guidelines of the University of Szeged.

2.2. Experimental Design. The animals were randomly divided into four groups: 1: sedentary control (nonrunning non-colitis-induced, $n=13$ ), 2: running control (running non-colitis-induced, $n=18)$, 3: sedentary TNBS $(n=14)$, and 4: running TNBS groups $(n=18)$ (Figure 1$)$. Rats of the running groups were placed in cages with a running wheel (Acellabor Ltd., Budapest, Hungary). Before the beginning of experimental period rats were allowed to accommodate to the running wheel for a week. The activity of the rats on the running wheel was monitored by a bicycle computer attached to each wheel. After 6 weeks of self-administered physical exercise colitis was induced by 2,4,6-trinitrobenzene sulphonic acid (TNBS; once $10 \mathrm{mg}$ in $0.25 \mathrm{~mL}$ of $50 \%$ ethanol, w/v). The intracolonic administration of TNBS was performed with an $8 \mathrm{~cm}$ long plastic catheter under transient ether anaesthesia (the method originally described by Morris et al. [21]). The control groups did not receive any treatment. Physical activity was continued following TNBS treatment. Rats were weighed twice a week until the induction of colitis and then daily following the TNBS challenge. 72 hours after the induction of colitis the animals were sacrificed and the distal $8 \mathrm{~cm}$ portion of the colon was dissected, longitudinally opened, gently rinsed with ice-cold physiological saline, and photographed (Panasonic Lumix DMC-TZ6, digital camera) for the determination of macroscopic colonic inflammatory damage. The colon was weighed and divided into longitudinal segments to be used for the following molecular and biochemical analyses.

\subsection{Damage Score and Lesion Measurement. The extent} of macroscopically apparent inflammation, ulceration, and tissue disruption was determined in a randomized manner from the colour images, using a proprietary computerized planimetry software, developed in our laboratory (Stat_2_1_1). The area of macroscopically visible mucosal involvement was calculated and expressed as the percentage of the total colonic segment area under study.

The degree of colonic inflammation was scored on a $0-11$ scale in a randomized, blinded fashion. The criteria has been adapted from what has been used previously: $0=$ no damage, $1=$ focal hyperemia and no ulcers, $2=$ ulceration without hyperemia or bowel wall thickening, $3=$ ulceration with inflammation at 1 site, $4=$ more than 2 sites of ulceration and inflammation, $5=$ more than 2 major sites of ulceration and inflammation or 1 site of ulceration/inflammation extending 


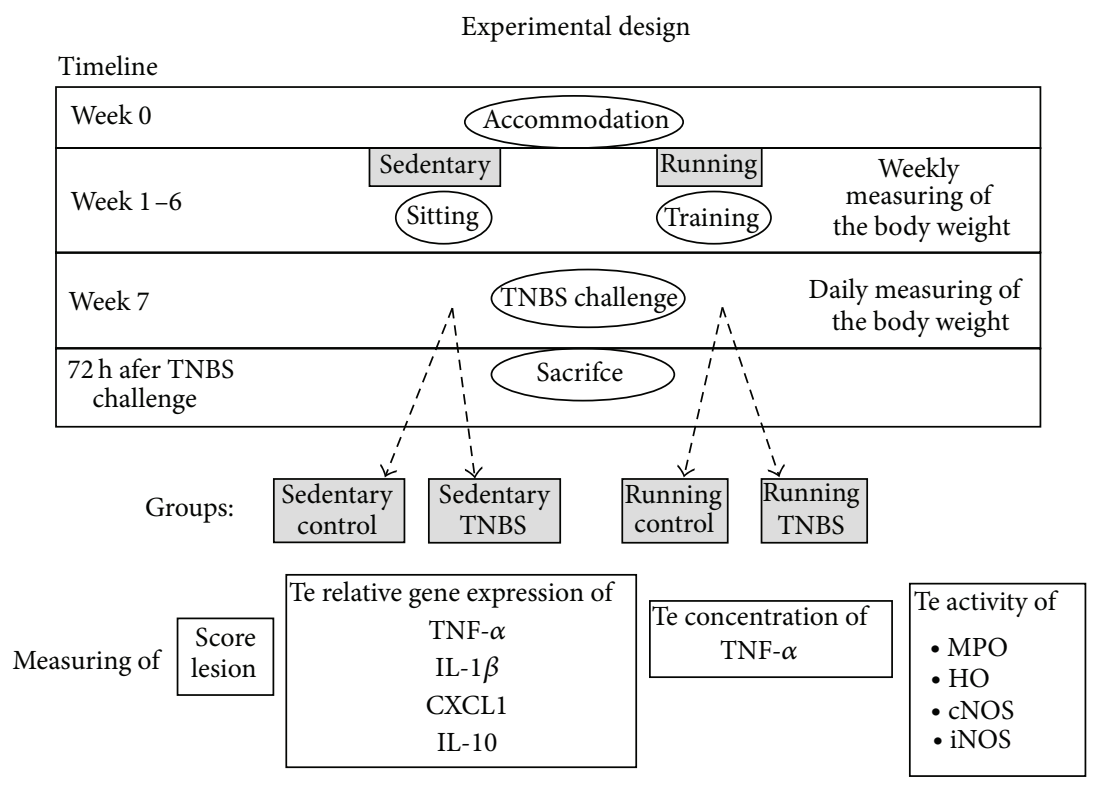

FIgURE 1: Diagram showing the experimental design.

$>1 \mathrm{~cm}$ along the length of the colon and $6-11=$ the score is increased by 1 for each additional centimetre of involvement [14].

2.4. Quantification of TNF- $\alpha$ Protein with the AlphaLISA Assay. The rat large intestine was immediately frozen in liquid nitrogen after dissection. During protein extraction the tissues were stored on ice. We used $1 \mathrm{~mL}$ RIPA buffer (150 mM NaCl (Molar Chemicals, Budapest, Hungary), $1 \%$ Nonidet P-40 (Sigma-Aldrich), 0.5\% Na-deoxycholate (Sigma-Aldrich), $0.1 \%$ sodium dodecyl sulfate (SigmaAldrich), and $50 \mathrm{mM}$ Tris- $\mathrm{HCl}$ (pH 8.0) (Molar Chemicals)) for protein extraction from $40 \mathrm{mg}$ tissue, supplemented with $20 \mu \mathrm{L}$ NEM (N-ethyl-maleinimide) and $20 \mu \mathrm{L}$ phenylmethane-sulfofluoride (PMSF) protease inhibitors. We homogenized the tissue samples with Ultra-Turrax T25 (IKA-Labortechnik, Staufen, Germany) tissue homogenizer on ice for $1 \mathrm{~min}$. The homogenates were centrifuged for $10 \mathrm{~min}$ at $10.000 \times \mathrm{g}$ at $4^{\circ} \mathrm{C}$ and the concentration of the supernatant was measured with a NanoDrop ND-1000 spectrophotometer (NanoDrop Technologies, Wilmington, USA). All samples were then diluted to a uniform $0.5 \mathrm{mg} / \mathrm{mL}$ concentration. Until further analyses samples were stored at $-20^{\circ} \mathrm{C}$ (stock samples were stored at $-80^{\circ} \mathrm{C}$ ).

For the quantification of TNF- $\alpha$, we used the AlphaLISA bead based technique, which was developed and is supported by Perkin Elmer (Perkin Elmer, Massachusetts, USA). Alpha Technology is a highly sensitive assay ideal for the measurement of protein interaction. We used $5 \mu \mathrm{L}$ volume from $0.5 \mathrm{mg} / \mathrm{mL}$ protein solution. The final amount of AlphaLISA Anti-Analyte Acceptor beads was set at $10 \mu \mathrm{g} / \mathrm{mL}$ concentration, while the final amount of Streptavidin-Donor beads was set at $40 \mu \mathrm{g} / \mathrm{mL}$. The final working concentration of Biotinylated Antibody Anti-Analyte was $1 \mathrm{nM}$. All incubations were under subdued laboratory lighting (<100 lux).
The samples were measured in $50 \mu \mathrm{L}$ final volume filled in 384-well polystyrene plates (Tomtec Plastik, Budapest, Hungary) with an EnVision-Alpha Reader (PerkinElmer).

2.5. Myeloperoxidase Activity. To measure myeloperoxidase activity we employed a modification of the method described by Bradley et al. [22]. The $8 \mathrm{~cm}$ longitudinal strips of the colon were weighed, homogenized (Ultra-Turrax T25 IKA-Labortechnik, $13.500 \mathrm{rev} / \mathrm{min}$, twice for $30 \mathrm{~s} ; 250 \mathrm{mg}$ colon/mL buffer) in ice-cold phosphate buffer $(50 \mathrm{mM}$, $\mathrm{pH}$ 6.0), containing $0.5 \%$ hexadecyltrimethylammoniumbromide, freeze-thawed three times, and then centrifuged at $10.000 \times \mathrm{g}$ for $15 \mathrm{~min}$ at $4^{\circ} \mathrm{C}$. A $12 \mu \mathrm{L}$ aliquot of the supernatant was then mixed with $280 \mu \mathrm{L}$ phosphate buffer $(50 \mathrm{mM}, \mathrm{pH}$ 6.0), containing $0.167 \mathrm{mg} / \mathrm{mL} \mathrm{O}$-adenosine dihydrochloride (Sigma-Aldrich), and the reaction was started with $10 \mu \mathrm{L}$ $0.03 \%$ hydrogen peroxide and assayed spectrophotometrically at $490 \mathrm{~nm}$ after $90 \mathrm{sec}$ shaking (Benchmark Microplate Reader, Bio-Rad Labs, Hercules, CA). MPO activity was expressed as $\mathrm{mU} / \mathrm{mg}$ protein.

2.6. Heme Oxygenase Activity. Heme oxygenase activity was assessed by measuring bilirubin formation with slight modifications form what has been described by Tenhunen et al. [23]. The segment of the colon was homogenized (Ultra-Turrax T25; 13.500/s; twice for $30 \mathrm{sec}$ ) in ice-cold $10 \mathrm{mM}$ N-[2-hydroxyethyl] piperazine- $\mathrm{N}^{\prime}$-[2-ethanesulfonic acid] (HEPES, Sigma-Aldrich), $32 \mathrm{mM}$ sucrose (SigmaAldrich), $1 \mathrm{mM}$ dithiothreitol (DTT, Sigma-Aldrich), $0.1 \mathrm{mM}$ EDTA, $10 \mu \mathrm{g} / \mathrm{mL}$ soybean trypsin inhibitor (Sigma-Aldrich), $10 \mu \mathrm{g} / \mathrm{mL}$ leupeptin (Sigma-Aldrich), and $2 \mu \mathrm{g} / \mathrm{mL}$ aprotinin (Sigma-Aldrich), at $\mathrm{pH}$ 7.4. The supernatant was collected by centrifugation for $30 \mathrm{~min}$ at $20.000 \times \mathrm{g}$ at $4^{\circ} \mathrm{C}$. Incubation was carried out in the dark at $37^{\circ} \mathrm{C}$ for $60 \mathrm{~min}$ with the reaction mixture containing the following ingredients in a 
final volume of $1.5 \mathrm{~mL}: 2 \mathrm{mM}$ glucose 6-phosphate (SigmaAldrich), $0.14 \mathrm{U} / \mathrm{mL}$ glucose 6-phosphate dehydrogenase (Sigma-Aldrich), $15 \mu \mathrm{M}$ heme, $150 \mu \mathrm{M} \beta$-nicotinamide adenine dinucleotide phosphate ( $\beta$-NADPH, Sigma-Aldrich), $120 \mu \mathrm{g} / \mathrm{mL}$ rat liver cytosol as a source of biliverdin reductase, $2 \mathrm{mM} \mathrm{MgCl}_{2}, 100 \mathrm{mM}$ potassium phosphate buffer, and $150 \mu \mathrm{L}$ of supernatant. The reaction was stopped by placing the samples on ice. The bilirubin formed was calculated from the difference between optical densities obtained at 460 and $530 \mathrm{~nm}$. One unit of heme oxygenase activity was defined as the amount of bilirubin (nmol) produced/hour/mg protein.

2.7. Nitric Oxide Synthase Activity. Nitric oxide synthase activity was determined by quantifying the conversion of $\left[{ }^{14} \mathrm{C}\right]$-radiolabelled L-arginine to citrulline by a previously described method with some minor modifications [24]. A segment of colon was homogenized as described for $\mathrm{HO}$ activity. Homogenates were centrifuged for $30 \mathrm{~min}$ at $20.000 \times \mathrm{g}$ at $4^{\circ} \mathrm{C}$. Samples $(40 \mu \mathrm{L})$ were incubated for $10 \mathrm{~min}$ at $37^{\circ} \mathrm{C}$ in $100 \mu \mathrm{L}$ of assay buffer $\left(50 \mathrm{mM} \mathrm{KH}_{2} \mathrm{PO}_{4}, 1.0 \mathrm{mM}\right.$ $\mathrm{MgCl}_{2}, 50 \mathrm{mM}$ L-valine, $0.2 \mathrm{mM} \mathrm{CaCl}$, $1.0 \mathrm{mM}$ DTT, $1.0 \mathrm{mM}$ L-citrulline, $15.5 \mathrm{nM}$ L-arginine, $30 \mu \mathrm{M}$ flavin adenine dinucleotide, $30 \mu \mathrm{M}$ flavin mononucleotide, $30 \mu \mathrm{M}$ tetrahydroL-biopterin dihydrochloride, $450 \mu \mathrm{M} \beta$-NADPH, and $12 \mathrm{pM}$ of $\left[{ }^{14} \mathrm{C}\right]$-L-arginine monohydrochloride (all from SigmaAldrich)). The reaction was terminated by the addition of $0.5 \mathrm{~mL}$ of $1: 1(\mathrm{v} / \mathrm{v})$ suspension of ice-cold DOWEX $\left(\mathrm{Na}^{+}\right.$form) in distilled water. The mixture was resuspended with the addition of $850 \mu \mathrm{L}$ of ice-cold distilled water. The supernatant $(970 \mu \mathrm{L})$ was removed and radioactivity was determined by scintillation counting. Calcium-dependency of the NOS activity was determined by the addition of $10 \mu \mathrm{L}$ of ethylene glycol-bis ( $\beta$-aminoethyl ether) tetraacetic acid (EGTA; $1 \mathrm{mM}$, Sigma-Aldrich). NOS activity was confirmed by inhibition with $10 \mu \mathrm{L}$ of $\mathrm{N} \omega$-nitro-L-arginine-methylester (LNNA; 3.7 mM, Sigma-Aldrich). Inducible NOS was defined as the citrulline formation that was inhibited by LNNA, but not by EGTA. The constitutive NOS activity was calculated from the difference between citrulline formation that was inhibited by EGTA and the total activity. As the nature of the constitutive isoform (eNOS or nNOS) was not determined, this activity is referred to as cNOS. NOS activity was expressed as $\mathrm{pmol} / \mathrm{min} / \mathrm{mg}$ protein.

2.8. Protein Determination for HO, NOS, and MPO Activity. Using a commercial protein assay kit (Bio-Rad Labs), aliquots $(20 \mu \mathrm{L})$ of the diluted samples $(15 \times$ or $25 \times$ with distilled water) were mixed with $980 \mu \mathrm{L}$ of distilled water with $200 \mu \mathrm{L}$ Bradford reagent added to each sample. After mixing and following $10 \mathrm{~min}$ incubation, the samples were assayed spectrophotometrically at $595 \mathrm{~nm}$. Protein level was expressed as $\mathrm{mg}$ protein $/ \mathrm{mL}$.

2.9. RNA Extraction, Reverse Transcription, and Quantitative Reverse Transcriptase Polymerase Chain Reaction (QPCR). The samples were homogenized in $1 \mathrm{~mL}$ of TRIzol reagent (Life Technologies, Carlsbad, CA) with ultra-turrax T-18 basic homogenizer $(2 \times 30 \mathrm{sec}$ at $5000 \mathrm{rpm})$; one-third volume of chloroform (Sigma-Aldrich) was added to the suspension with vigorous vortexing. Samples were centrifuged at $13000 \mathrm{rpm}$ for 10 minutes and total RNA was extracted from the upper phase by using RNeasy Plus Mini Kits (Qiagen, Germany) according to the manufacturer's protocol. In parallel, peripheral blood mononuclear cells (PBMC) were isolated from the blood of the same animals by Ficoll Paque Plus (GE Healthcare, UK) density gradient centrifugation. Total RNA from PBMC was also extracted using RNeasy Plus Mini Kits (Qiagen). The quality and quantity of isolated RNA were determined using NanoDrop and Bioanalyzer (Agilent, Santa Clara, USA) measurements.

cDNA was synthesized from $100 \mathrm{ng}$ of total RNA by using High Capacity RNA to cDNA Kit or SuperScript Vilo cDNA Synthesis Kit (both from Life Technologies) according to the manufacturer's instructions. cDNA levels were determined by QPCR using StepOne Plus Real-Time PCR System (Life Technologies). Reactions were performed with Power SybrGreen Master Mix (Life Technologies) with the following primer sets:

\section{TNF- $\alpha$ sense: GCTCCCTCTCATCAGTTCCA, TNF- $\alpha$ antisense: GGCTTGTCACTCGAGTTT- TGA; \\ CXCL1 sense: CATTAATATTTAACGATGTGGAT- GCGTTTCA, \\ CXCL1 antisense: GCCTACCATCTTTAAACT- GCACAAT [25]; \\ IL- $1 \beta$ sense: CAGGAAGGCAGTGTCACTCA, \\ IL- $1 \beta$ antisense: AGACAGCACGAGGCATTTTT; \\ IL-10 sense: CCTGCTCCTACTGGCTGGAG, \\ IL-10 antisense: TTGTTCAGCTGGTCCTTCTT.}

To avoid false-positive results due to amplification of contaminating genomic DNA in the cDNA preparation, we used primers spanning exon-exon junctions. All measurements were performed in duplicates with at least four biological replicates. The ratio of each mRNA relative to the $18 \mathrm{~S}$ rRNA (assay ID: Hs99999901; Life Technologies) was calculated using the $\Delta \Delta C_{T}$ method.

2.10. Data Representation and Statistical Analysis. Results of the body weight change, damage score, lesion, and the activity of MPO, HO, cNOS, and iNOS are shown as mean \pm S.E.M; statistical comparisons were performed by twotailed Student's $t$-test. Statistical analysis of the TNF- $\alpha$ protein secretion was performed using one-way ANOVA. QPCR data are presented as data points and median; the significance of the differences between samples was determined by applying the Newman-Keuls test using GraphPad Prism for Windows. In all statistical comparisons, a probability $(P)$ value of less than 0.05 was considered significant.

\section{Results}

3.1. Alteration of Body Weight after Running and TNBS Treatment. Running distance averaged 2600 meters/day/rat. 


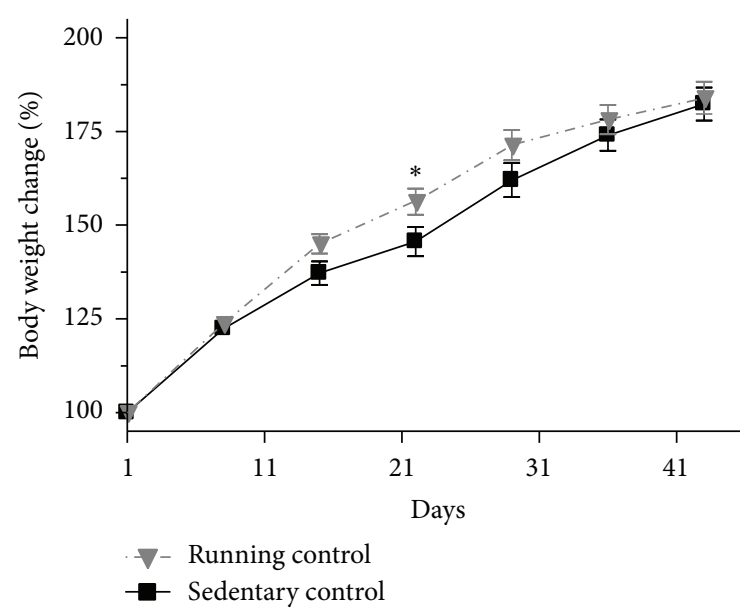

(a)

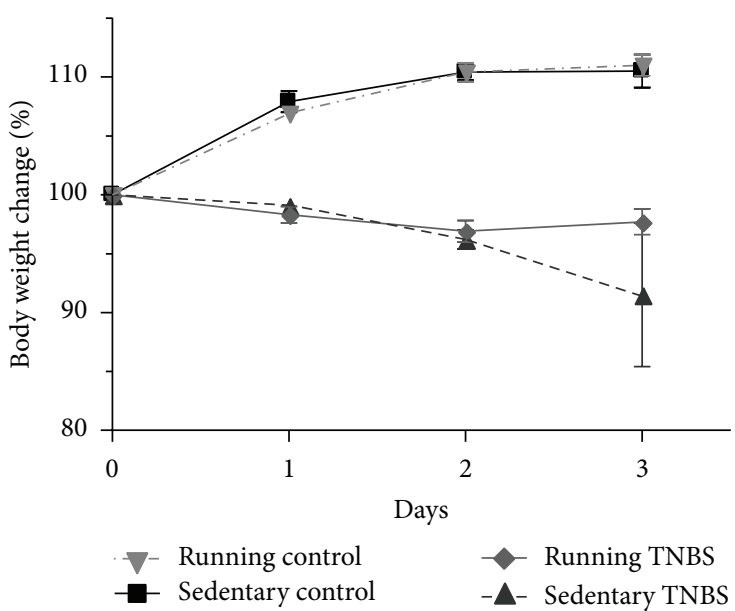

(b)

FIGURE 2: Body weight changes during the 6 weeks of running (a) and after the TNBS treatment (b). Results are shown as mean \pm S.E.M. $\left({ }^{*} \mathrm{P}<0.05\right.$ compared to the sedentary nontreated control group, $\left.n=34-43\right)$.

We did not find any differences between the body weights of sedentary and running groups during the 6 weeks of exercise before TNBS administration (Figure 2(a)). On the other hand, there was a progressive decrease in body weight after the induction of colonic inflammation in the TNBS treated groups (Figure 2(b)).

3.2. Effects of 6-Week Running and TNBS Challenge on Damage Score, Mucosal Lesions, and MPO Activity. The severity of mucosal damage was scored on a $0-11$ scale by a randomized, blinded fashion. 6 weeks of running before the TNBS challenge significantly $(P<0.001)$ decreased the level of this inflammatory damage score marker from $7.6 \pm 0.3$ to $6.6 \pm 0.3$ (Figure 3(a)).

Challenge with TNBS caused hemorrhagic and necrotic damage of the colonic mucosa, as determined macroscopically 72 hours after TNBS administration. In the sedentary, nonrunning group the level of damage reached $54.6 \pm 2.63 \%$ of the total colonic area. We detected a significant decrease $(42.9 \pm 3.21 \%, P<0.01)$ in macroscopic injury in the colons of the trained, TNBS-treated group (Figures 3(b) and 3(c)).

Following treatment with TNBS, there was a thirtyfold increase in colonic MPO activity, suggesting massive neutrophil infiltration [22]. Wheel running significantly $(P<$ 0.01 ) attenuated the elevation of MPO activity from $880.6 \pm$ 79.3 to $568.4 \pm 59.9 \mathrm{mU} / \mathrm{mg}$ protein (Figure 4 ).

3.3. The Effect of Physical Exercise on the Gene Expression Profiles of Selected Pro- and Anti-Inflammatory Mediators in TNBS-Induced Experimental Acute Colitis. In PBMCs, the physical exercise alone significantly $(P<0.05)$ downregulated the gene expression of IL-1 $\beta$, CXCL1 and IL-10 as compared to the inactive group (Figure 5(a)). TNBS treatment alone only downregulated the expression of CXCL1, and had no effect on the expression of TNF- $\alpha$, IL- $1 \beta$, and IL10 transcripts. Interestingly, exercise before TNBS treatment downregulated the expression of CXCL1 and IL-10. Notably, the downregulation of IL-10 was significant as compared to not only absolute controls but also to TNBS treatment alone (Figure 5(a)).

In contrast to the downregulated expression pattern detected in PBMCs, physical exercise alone did not alter the gene expression of the monitored inflammatory mediators in the colon when compared to sedentary controls (Figure 5(b)). Yet, TNBS treatment alone induced marked upregulation $(P<0.05)$ in the expression of pro- but not anti-inflammatory mediators (IL-1 $\beta$, CXCL1, and IL-10, resp.) in the colon. Furthermore, exercise significantly attenuated TNBS-induced upregulation of proinflammatory mediators (IL-1 $\beta$, CXCL1) and significantly increased expression of antiinflammatory IL-10 (Figure 5(b)).

3.4. Effect of Running and/or TNBS Challenge on Colonic TNF- $\alpha$ Protein Content. 6-week running had no significant effect on the colonic content of TNF- $\alpha$. In the inflamed colons we found a doubling of TNF- $\alpha$ concentration in the sedentary group $(578.4 \pm 118.47 \mathrm{pg} / \mathrm{mL})$, and although 6 -week running before TNBS treatment slightly decreased TNF- $\alpha$ levels (496.16 $\pm 87.77 \mathrm{pg} / \mathrm{mL})$, the decrease was not significant compared to the sedentary TNBS group (Figure 6(a)).

\subsection{Changes in Colonic HO Activity by Physical Exercise} and/or TNBS Treatment. Voluntary physical exercise significantly increased $\mathrm{HO}$ activity from $1.3 \pm 0.2$ to $2.8 \pm$ $0.3 \mathrm{nmol}$ bilirubin $/ \mathrm{h} / \mathrm{mg}$ protein $(P<0.001)$. Treatment with TNBS alone led to even higher $\mathrm{HO}$ activity $(6.9 \pm 0.4 \mathrm{nmol}$ bilirubin/h/mg protein, $P<0.001$ ), after 6 weeks of exercise slightly increased the $\mathrm{HO}$ activity, but this difference was not significant between the running TNBS group and the nonrunning TNBS group (Figure 6(b)).

3.6. Effects of TNBS Treatment and/or Physical Exercise on Colonic cNOS Activity. The 6-week running alone caused a significant $(P<0.05)$ increase in cNOS activity. 


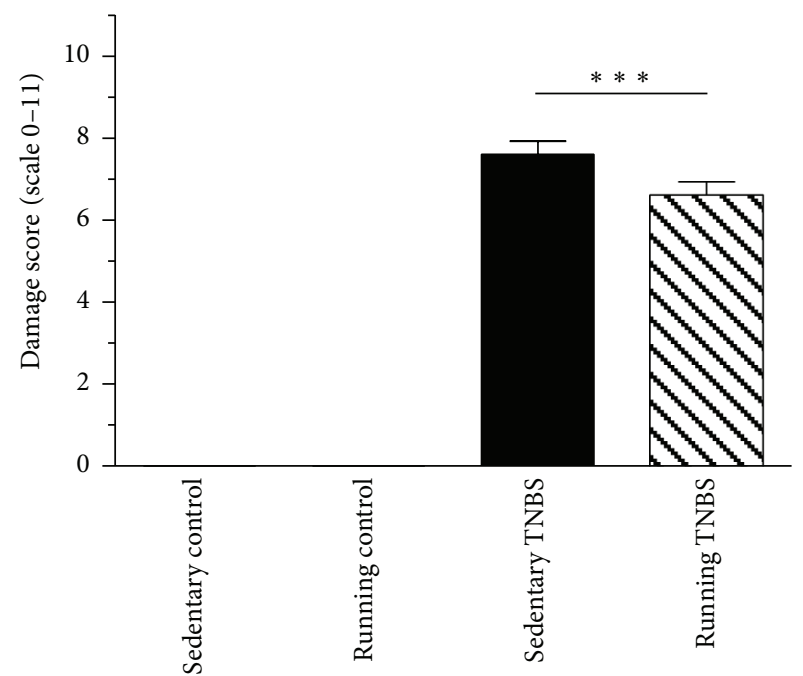

(a)

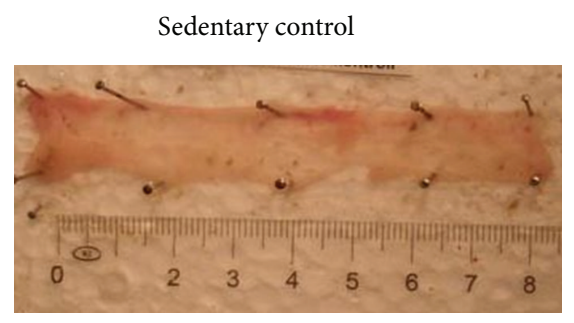

Running control

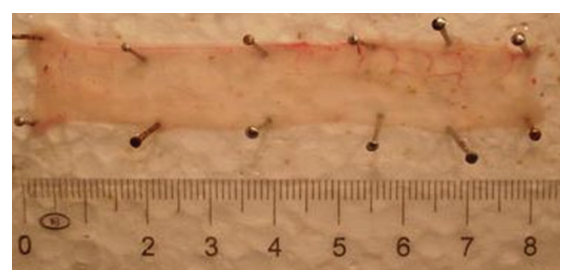

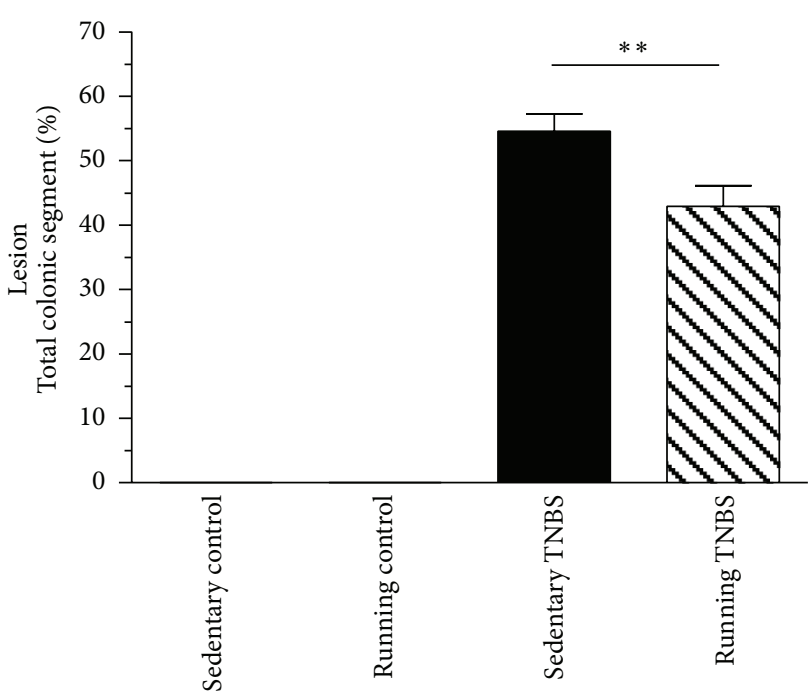

(b)

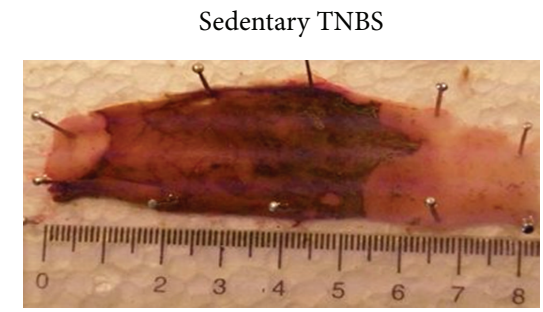

Running TNBS

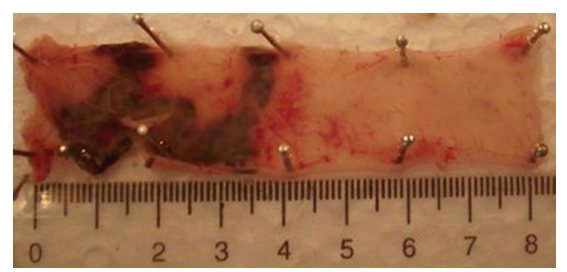

c)

FIGURE 3: Effects of 6 weeks of running on macroscopic colonic inflammatory damage score (a) and lesion (b) in TNBS-induced colitis after 72 hrs. Results are shown as mean \pm S.E.M. $\left({ }^{* *} P<0.01\right.$ and ${ }^{* * *} P<0.001$ compared to the sedentary TNBS group, $\left.n=13-19\right)$. Representative images of freewheel running and induction of colonic inflammation: sedentary control, and running control, sedentary TNBS, running TNBS (c).

In the nonrunning TNBS group we have measured a significantly decreased $(P<0.001)$ cNOS activity (from $321.1 \pm 35.16$ to $108.9 \pm 25.6 \mathrm{pmol} / \mathrm{min} / \mathrm{mg}$ protein) compared to the nontreated control group. Voluntary exercise before TNBS administration significantly $(P<0.001)$ augmented cNOS activity from $108.9 \pm 25.6$ to $333.9 \pm$ $32.3 \mathrm{pmol} / \mathrm{min} / \mathrm{mg}$ protein compared to the nonrunning TNBS group (Figure $7(\mathrm{a})$ ).

3.7. Effects of TNBS Treatment and/or Physical Exercise on Colonic iNOS Activity. Inflammation caused by TNBS challenge significantly elevated $(P<0.01)$ iNOS activity (from $21.4 \pm 5.49$ to $217.5 \pm 26.43 \mathrm{pmol} / \mathrm{min} / \mathrm{mg}$ protein) independently of exercise. Importantly, the 6-week running before TNBS treatment significantly $(P<0.05)$ reduced this increase of iNOS activity from $217.5 \pm 26.43$ to $128.9 \pm$ $15.82 \mathrm{pmol} / \mathrm{min} / \mathrm{mg}$ protein (Figure 7(b)).

\section{Discussion}

The results of the present study demonstrate that 6-week physical exercise before TNBS challenge can ameliorate the severity and extent of colonic damage caused by TNBS treatment in rats by downregulating the expression of proinflammatory mediators, inducing the expression of antiinflammatory mediators, and affecting the activity of cNOS and iNOS enzymes.

In this study we used the 2,4,6-trinitrobenzene-sulfonicacid- (TNBS-) induced rat acute colitis model, in which the inflammatory response is due to the generation of transmural 


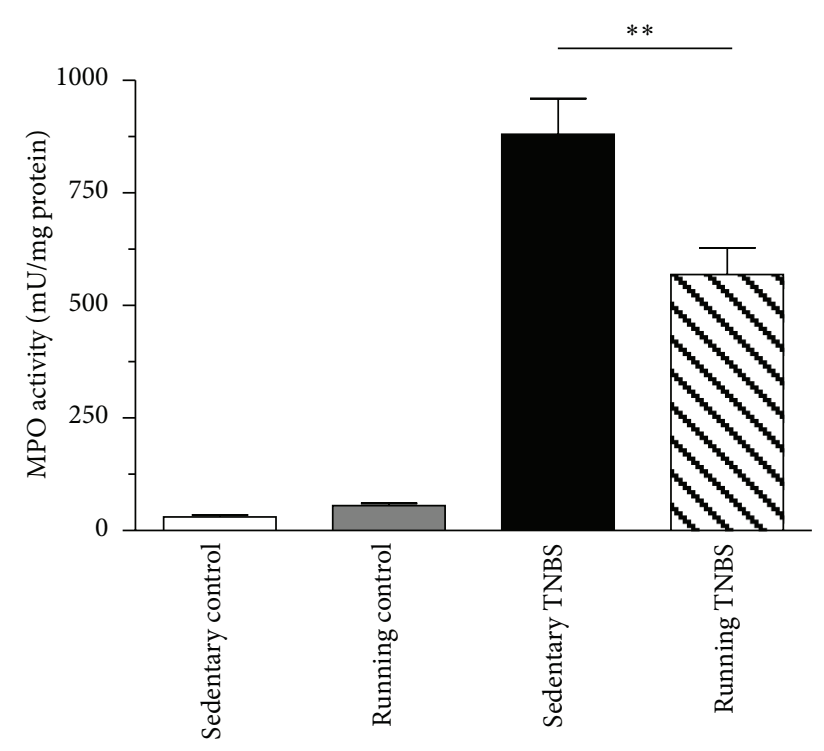

FIGURE 4: MPO activity in rats treated with TNBS after 6 weeks of resting or 6 weeks of running. Results are shown as mean \pm S.E.M. $\left({ }^{* *} P<0.01\right.$ compared to the sedentary TNBS group, $\left.n=7-16\right)$.

oxidative stress and release of proinflammatory mediators $[26,27]$. We used a voluntary wheel running model to mimic leisure-type physical exercise, which induces lower degree of stress compared to swimming or treadmill exercise protocols due to the reduced handling of animals and stress-inducing exercise motivators [28].

The body weights after 6 weeks of running did not show any differences compared to the nonrunning groups, however, body composition was not examined.

Intracolonic administration of TNBS causes an acute, severe, transmural inflammation, which mimics several clinical and morphological features of Crohn's disease [26]. In the sedentary colitis group on average, $50 \%$ of the $8 \mathrm{~cm}$ colonic portion was inflamed with ulceration and we have also found a 30-fold elevation in MPO activity.

In order to determine if gene expression changes of PBMCs reflect that of the inflamed colon, we have monitored the gene expression changes of well-known inflammatory markers. Interestingly, we found that 6 weeks of running alone downregulated the expression of both pro- and antiinflammatory mediators (IL-1 $\beta$, CXCL1, and IL-10, resp.) in PMBCs but not in the colon. In addition, in the colon physical exercise only attenuated the expression level of antiinflammatory IL-10 compared to sedentary TNBS-treated animals.

In contrast to PBMCs, TNBS induced marked upregulation of proinflammatory cytokines IL- $1 \beta$ and CXCL1 in the colon, which is in good agreement with previous studies showing elevated expression of these molecules in IBD [6]. Importantly, recreational physical exercise downregulated TNBS-induced expression of both cytokines. In parallel, we detected markedly elevated IL-10 expression in running TNBS animals. These observations, together with those showing decreased level of damage score in physically active animals, suggest that physical activity indeed ameliorates the extent of the inflammation caused by TNBS. However, it remains to be determined if physical activity shows a similar protective effect in patients with chronic IBD.

Although there was no change in TNF- $\alpha$ gene expression we found a significantly increased TNF- $\alpha$ protein content in the inflamed colon with TNBS in accordance with earlier findings $[26,29]$. We hypothesize that polymorphism in TNF- $\alpha$ promoter regions could be responsible for discrepancies between gene and protein expression level [30]. However, no significant decrease in TNF- $\alpha$ protein content was seen after exercise in the TNBS-treated group compared to the nonrunning TNBS-treated group. It is feasible that exercise impacts inflammation through pathways other than TNF- $\alpha$, because several other markers were attenuated in our study, indicating the effectiveness of this intervention against IBD.

The elevated $\mathrm{HO}$ activity suggests the involvement of oxidative stress in colonic damage. Earlier findings demonstrated the ability of chemically induced $\mathrm{HO}$ to reduce the extent and intensity of experimental colonic inflammation [14]. Several studies demonstrated that long-lasting exercise can induce antioxidant mechanisms in a variety of tissues, probably as a defensive response to oxidative stress [31]. Brooks et al. [32] demonstrated that 8 weeks of treadmill running reduced the release of ROS and NO from contracting muscles and increased skeletal muscle antioxidant content such as glutathione and protein thiols in mice. George et al. [33] found an elevated activity and expression of superoxide dismutase and HO-1 in the plasma and renal proximal tubules of rats after treadmill training for 12 weeks. Our observations that a 6-week voluntary exercise can induce colonic $\mathrm{HO}$ activity also agree with previous data, supporting the antioxidant effects of moderate training. Along these lines, Kasimay et al. demonstrated the protective role of 6 weeks of wheel running against oxidative colonic injury in a model of acetic acidinduced intestinal inflammation [34].

We found opposite changes of cNOS and iNOS activity in the inflamed colon. Our observations of decreased cNOS and increased iNOS activity in the sedentary colitis group are also consistent with previous findings. We do not know to what extent the two constitutive isoforms (nNOS and eNOS) are responsible for the reduction of cNOS activity. Experiments with eNOS deficient mice show the important role of the other constitutive NOS isoform in limiting intestinal injury in IBD [35]. In IBD nNOS is downregulated, while iNOS expression increases cyclically during the active phase of inflammation. Excess NO produced by iNOS can generate the prooxidant peroxynitrite [36]. This overproduction of NO by upregulation of iNOS seems to be responsible for the observed intestinal hypomotility and subsequent bacterial overgrowth [18].

We presented that rat colonic cNOS activity increased, while iNOS activity remained unchanged with exercise compared to the sedentary control group. Together with the observed expression changes induced by TNBS, it appears that prior exercise is able to mitigate colonic inflammation and macroscopic damage by maintaining cNOS and attenuating iNOS expression in IBD. These observations are also in agreement with previous data, showing that regular physical activity induces increased eNOS gene expression and 

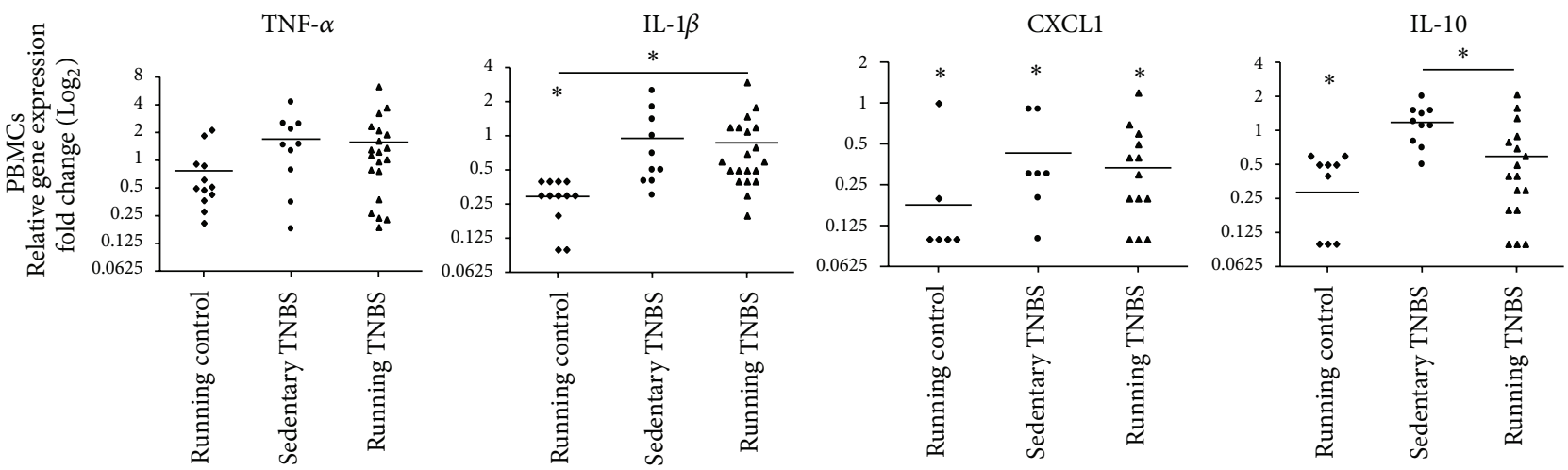

(a)

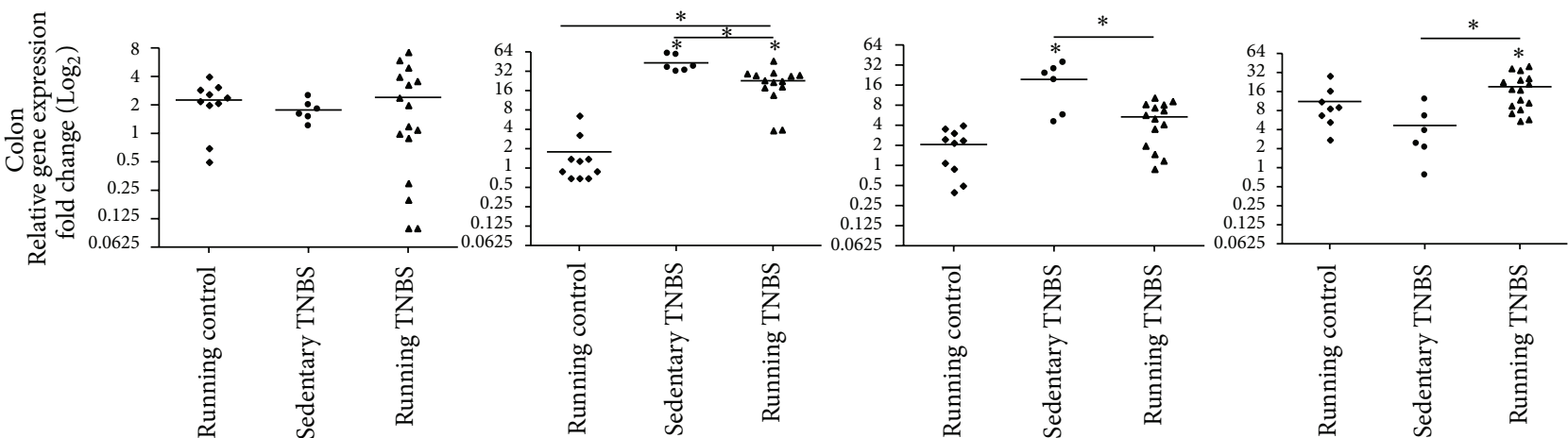

(b)

FIGURE 5: The relative gene expression of selected pro- and anti-inflammatory mediators in peripheral blood mononuclear cell (PBMC) (a) and colon (b). The expression pattern of TNF- $\alpha$, IL-1 $\beta$, CXCL1, and IL-10 from sedentary and running groups with or without TNBS treatment was determined with qPCR and compared to sedentary nontreated animals (absolute controls). Results are shown as data points and median $\left({ }^{*} P<0.05 ; n=6-20\right)$.

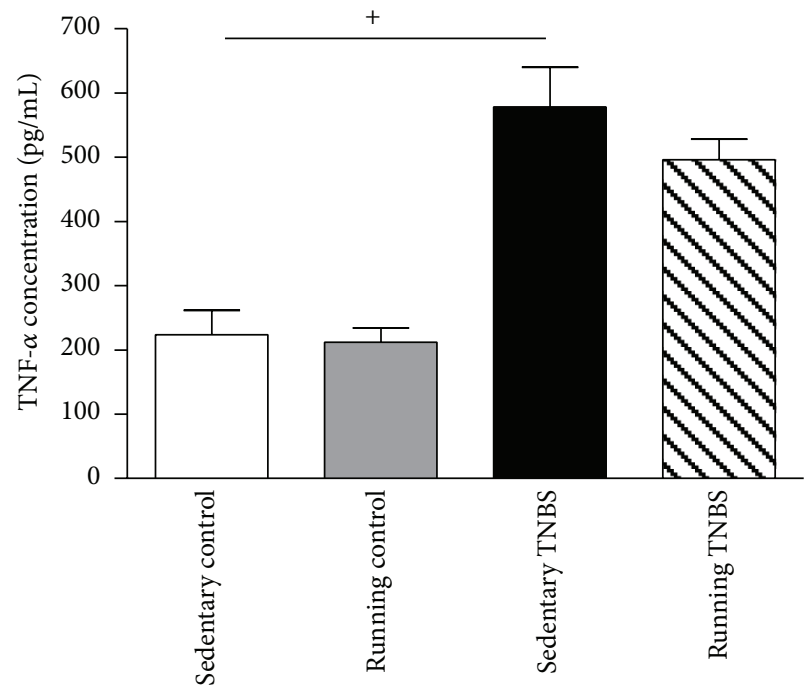

(a)

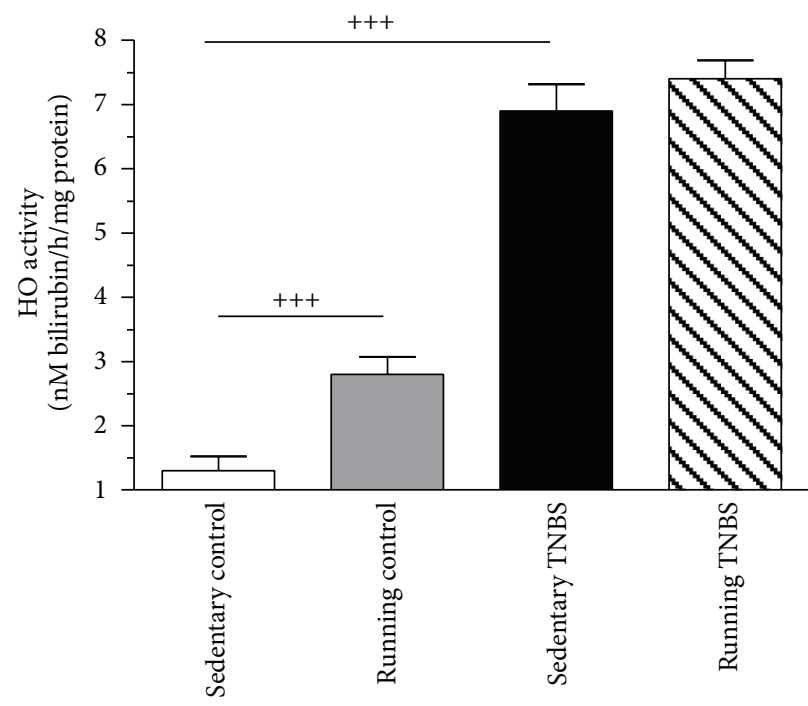

(b)

FIGURE 6: (a) Concentration of TNF- $\alpha$ in $1 \mathrm{~g}$ tissue in sedentary and running groups with or without TNBS treatment. Results are shown as mean \pm S.D. $\left({ }^{+} P<0.05 ; n=4-10\right)$. (b) Effects of 6 weeks of running on colonic HO activity either in the control group or in TNBS-induced colitis after 72 hrs. Results are shown as mean \pm S.E.M. $\left({ }^{++} P<0.001\right.$ compared to the sedentary nontreated control group, $\left.n=8-16\right)$. 


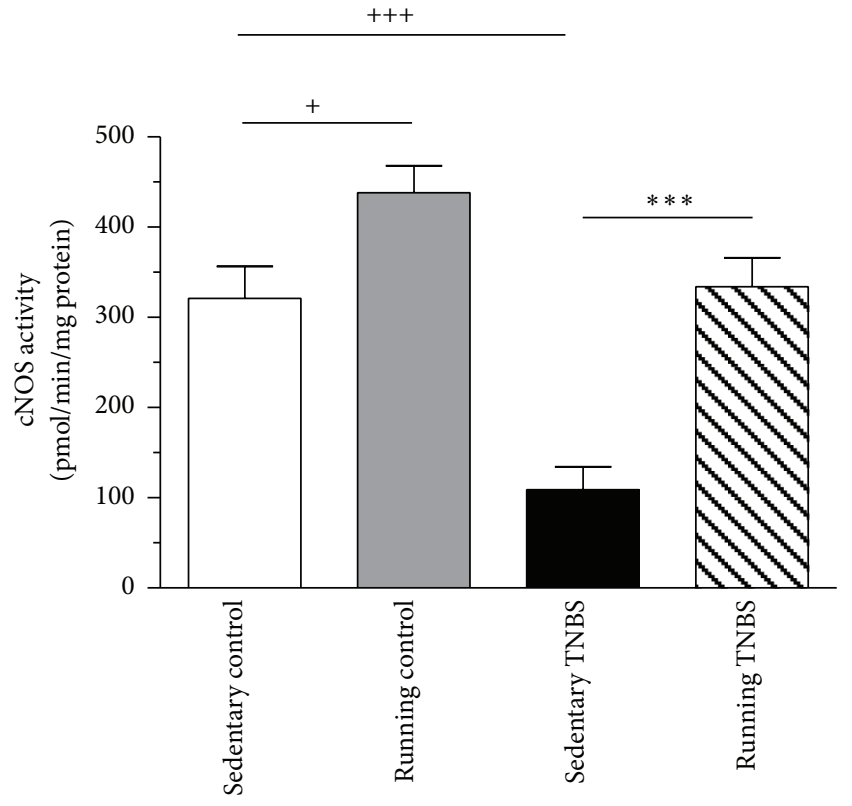

(a)

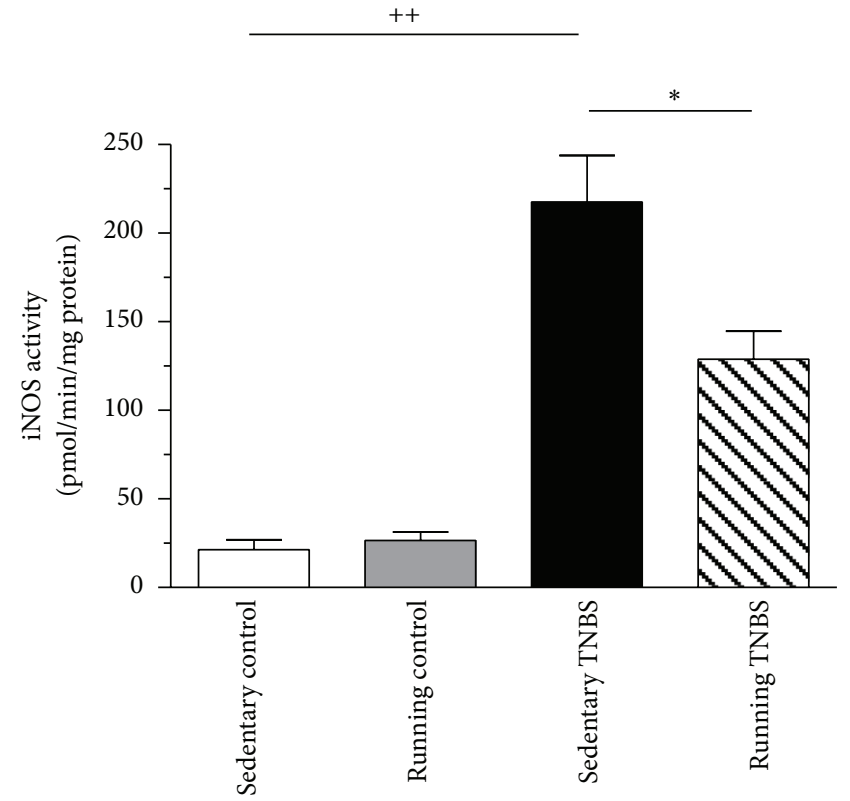

(b)

FIGURE 7: Effects of 6 weeks of running on colonic cNOS activity (a) and iNOS activity (b) either in the control group or in TNBS-induced colitis after $72 \mathrm{hrs}$. Results are shown as mean \pm S.E.M. $\left({ }^{+} P<0.05,{ }^{++} P<0.01\right.$, and ${ }^{+++} P<0.001$ compared to the sedentary control group and ${ }^{*} P<0.05,{ }^{* * *} P<0.001$ compared to the sedentary TNBS group, $\left.n=6-15\right)$.

reduces the expression of iNOS in CD34(+) PBMCs [37]. Moreover, NO-releasing derivative of aspirin can accelerate the healing of colonic inflammation in an animal model [38]. Our results are in agreement with earlier studies about naturally occurring compounds and drugs such as naringenin, a flavonoid in citrus, grapefruits, and tomatoes [39] 3,4-oxo-isopropylidene-shikimic acid [40] which has anti-inflammatory effect on experimental colitis through reduction of the expression of inflammatory cytokines and mediators such as iNOS. Therefore, it appears that the NO pathway plays a central role in the resolution of inflammation in IBD.

Exercise has been speculated to be protective against the onset of IBD, but the literature is inconsistent. Preliminary studies reveal that exercise training (relatively low intensity) may be beneficial to reduce stress and symptoms of IBD. Current research also recommends exercise to help counteract some IBD-specific complications by improving bone mineral density, immunological response, psychological health, weight loss, and stress management ability. However, the literature advises that some patients with IBD may have limitations to the amount and intensity of exercise that they can perform [2].

It has become clear that physical activity is not harmful for patients with inflammatory bowel disease, despite acute exercise related responses, such as increased serum malondialdehyde levels and activated neutrophils. In addition, physical activity may reduce disease activity and improve physical health, general well-being, and perceived stress. In summary, exercise may be beneficial to IBD patients, but further research is required to make a convincing conclusion regarding its role in the management of IBD and to help establish exercise regimens that can account for each IBD patient's unique presentation [2]. In conclusion, in the present study we aimed to investigate young adult rats, which are age-matched population to the incidence of IBD [41]. Our results suggest that exercise may be protective against the onset of IBD through the modulation of pro- and antiinflammatory and antioxidant mediators with $\mathrm{HO}$ and NOS enzymes playing a central role in these effects. Along these lines, regular exercise can promote healthy aging via the same mechanisms.

\section{Conflict of Interests}

The authors declare that there is no conflict of interests regarding the publication of this paper.

\section{Acknowledgments}

This work was supported by the Janos Bolyai Research Scholarship of the Hungarian Academy of Sciences (to Aniko Posa), by the Hungarian National Development Agency TÁMOP 4.2.2.-08/1-2008-0006 and TÁMOP 4.2.2/B-10/12010-0012 (to Zita Szalai) research grants. This research was realized in the frames of TÁMOP 4.2.4. A/2-11-1-2012-0001 (to Anikó Pósa, Kedvesne Krisztina Kupai, and Renáta Szabó) National Excellence Program-elaborating and operating an inland student and researcher personal support system. The project was subsidized by the European Union and cofinanced by the European Social Fund. 


\section{References}

[1] K. van Wijck, K. Lenaerts, J. Grootjans et al., "Physiology and pathophysiology of splanchnic hypoperfusion and intestinal injury during exercise: strategies for evaluation and prevention," The American Journal of Physiology-Gastrointestinal and Liver Physiology, vol. 303, no. 3, pp. G155-G168, 2012.

[2] N. Narula and R. N. Fedorak, "Exercise and inflammatory bowel disease," The Canadian Journal of Gastroenterology, vol. 22, no. 5, pp. 497-504, 2008.

[3] H. P. F. Peters, W. R. de Vries, G. P. Vanberge-Henegouwen, and L. M. A. Akkermans, "Potential benefits and hazards of physical activity and exercise on the gastrointestinal tract," Gut, vol. 48, no. 3, pp. 435-439, 2001.

[4] I. L. Huibregtse, A. U. van Lent, and S. J. H. van Deventer, "Immunopathogenesis of IBD: insufficient suppressor function in the gut?" Gut, vol. 56, no. 4, pp. 584-592, 2007.

[5] B. Khor, A. Gardet, and R. J. Xavier, "Genetics and pathogenesis of inflammatory bowel disease," Nature, vol. 474, no. 7351, pp. 307-317, 2011.

[6] I. Arijs, G. de Hertogh, K. Machiels et al., "Mucosal gene expression of cell adhesion molecules, chemokines, and chemokine receptors in patients with inflammatory bowel disease before and after infliximab treatment," The American Journal of Gastroenterology, vol. 106, no. 4, pp. 748-761, 2011.

[7] L. Kruidenier, I. Kuiper, C. B. H. W. Lamers, and H. W. Verspaget, "Intestinal oxidative damage in inflammatory bowel disease: semi-quantification, localization, and association with mucosal antioxidants," The Journal of Pathology, vol. 201, no. 1, pp. 28-36, 2003.

[8] B. Juhasz, P. Der, P. Szodoray et al., "Adrenocorticotrope hormone fragment (4-10) attenuates the ischemia/reperfusioninduced cardiac injury in isolated rat hearts," Antioxidants and Redox Signaling, vol. 9, no. 11, pp. 1851-1861, 2007.

[9] B. Juhasz, B. Varga, A. Czompa et al., "Postischemic cardiac recovery in heme oxygenase-1 transgenic ischemic/reperfused mouse myocardium," Journal of Cellular and Molecular Medicine, vol. 15, no. 9, pp. 1973-1982, 2011.

[10] A. Kertesz, M. Bombicz, D. Priksz et al., "Adverse impact of diet-induced hypercholesterolemia on cardiovascular tissue homeostasis in a rabbit model: time-dependent changes in cardiac parameters," International Journal of Molecular Sciences, vol. 14, no. 9, pp. 19086-19108, 2013.

[11] N. G. Abraham and A. Kappas, "Pharmacological and clinical aspects of heme oxygenase," Pharmacological Reviews, vol. 60, no. 1, pp. 79-127, 2008.

[12] M. P. Soares and F. H. Bach, "Heme oxygenase-1: from biology to therapeutic potential," Trends in Molecular Medicine, vol. 15, no. 2, pp. 50-58, 2009.

[13] C. Varga, F. Laszlo, P. Fritz et al., "Modulation by heme and zinc protoporphyrin of colonic heme oxygenase-1 and experimental inflammatory bowel disease in the rat," The European Journal of Pharmacology, vol. 561, no. 1-3, pp. 164-171, 2007.

[14] K. Horváth, C. Varga, A. Berkó, A. Pósa, F. László, and B. J. R. Whittle, "The involvement of heme oxygenase-1 activity in the therapeutic actions of 5-aminosalicylic acid in rat colitis," The European Journal of Pharmacology, vol. 581, no. 3, pp. 315-323, 2008.

[15] S. Adamopoulos, J. Parissis, D. Karatzas et al., "Physical training modulates proinflammatory cytokines and the soluble Fas/soluble Fas ligand system in patients with chronic heart failure," Journal of the American College of Cardiology, vol. 39, no. 4, pp. 653-663, 2002.

[16] M. Thirunavukkarasu, B. Juhasz, L. Zhan et al., "VEGFR1 (Flt$1^{+/-}$) gene knockout leads to the disruption of VEGF-mediated signaling through the nitric oxide/heme oxygenase pathway in ischemic preconditioned myocardium," Free Radical Biology and Medicine, vol. 42, no. 10, pp. 1487-1495, 2007.

[17] G. Kolios, V. Valatas, and S. G. Ward, "Nitric oxide in inflammatory bowel disease: a universal messenger in an unsolved puzzle," Immunology, vol. 113, no. 4, pp. 427-437, 2004.

[18] M. Porras, M. T. Martín, R. Torres, and P. Vergara, “Cyclical upregulated iNOS and long-term downregulated nNOS are the bases for relapse and quiescent phases in a rat model of IBD," The American Journal of Physiology-Gastrointestinal and Liver Physiology, vol. 290, no. 3, pp. G423-G430, 2006.

[19] M. Harpavat, D. J. Keljo, and M. D. Regueiro, "Metabolic bone disease in inflammatory bowel disease," Journal of Clinical Gastroenterology, vol. 38, no. 3, pp. 218-224, 2004.

[20] N. Lee, G. Radford-Smith, and D. R. Taaffe, "Bone loss in Crohn's disease: exercise as a potential countermeasure," Inflammatory Bowel Diseases, vol. 11, no. 12, pp. 1108-1118, 2005.

[21] G. P. Morris, P. L. Beck, M. S. Herridge, W. T. Depew, M. R. Szewczuk, and J. L. Wallace, "Hapten-induced model of chronic inflammation and ulceration in the rat colon," Gastroenterology, vol. 96, no. 3, pp. 795-803, 1989.

[22] P. P. Bradley, D. A. Priebat, R. D. Christensen, and G. Rothstein, "Measurement of cutaneous inflammation: estimation of neutrophil content with an enzyme marker," Journal of Investigative Dermatology, vol. 78, no. 3, pp. 206-209, 1982.

[23] R. Tenhunen, H. S. Marver, and R. Schmid, "The enzymatic conversion of heme to bilirubin by microsomal heme oxygenase," Proceedings of the National Academy of Sciences of the United States of America, vol. 61, no. 2, pp. 748-755, 1968.

[24] N. K. Boughton-Smith, S. M. Evans, F. Laszlo, B. J. R. Whittle, and S. Moncada, "The induction of nitric oxide synthase and intestinal vascular permeability by endotoxin in the rat," The British Journal of Pharmacology, vol. 110, no. 3, pp. 1189-1195, 1993.

[25] H. H. Tong, Y. Chen, X. Liu, and T. F. DeMaria, "Differential expression of cytokine genes and iNOS induced by nonviable nontypeable Haemophilus influenzae or its LOS mutants during acute otitis media in the rat," International Journal of Pediatric Otorhinolaryngology, vol. 72, no. 8, pp. 1183-1191, 2008.

[26] X.-Z. Shi, J. H. Winston, and S. K. Sarna, "Differential immune and genetic responses in rat models of Crohn's colitis and ulcerative colitis," The American Journal of PhysiologyGastrointestinal and Liver Physiology, vol. 300, no. 1, pp. G41G51, 2011.

[27] R. J. Xavier and D. K. Podolsky, "Unravelling the pathogenesis of inflammatory bowel disease," Nature, vol. 448, no. 7152, pp. 427-434, 2007.

[28] S. Ghosh, S. Golbidi, I. Werner, B. C. Verchere, and I. Laher, "Selecting exercise regimens and strains to modify obesity and diabetes in rodents: an overview," Clinical Science, vol. 119, no. 2, pp. 57-74, 2010.

[29] A. Saxena, E. Fletcher, B. Larsen, M. S. Baliga, J. L. Durstine, and R. Fayad, "Effect of exercise on chemically-induced colitis in adiponectin deficient mice," Journal of Inflammation, vol. 9, no. 1, article 30, 2012. 
[30] A. Mekinian, R. Tamouza, S. Pavy et al., "Functional study of TNF- $\alpha$ promoter polymorphisms: literature review and metaanalysis," The European Cytokine Network, vol. 22, no. 2, pp. 88102, 2011.

[31] S. K. Powers and M. J. Jackson, "Exercise-induced oxidative stress: cellular mechanisms and impact on muscle force production," Physiological Reviews, vol. 88, no. 4, pp. 1243-1276, 2008.

[32] S. V. Brooks, A. Vasilaki, L. M. Larkin, A. McArdle, and M. J. Jackson, "Repeated bouts of aerobic exercise lead to reductions in skeletal muscle free radical generation and nuclear factor $\kappa \mathrm{B}$ activation," The Journal of Physiology, vol. 586, no. 16, pp. 39793990, 2008.

[33] L. George, M. F. Lokhandwala, and M. Asghar, "Exercise activates redox-sensitive transcription factors and restores renal D1 receptor function in old rats," The American Journal of Physiology-Renal Physiology, vol. 297, no. 5, pp. F1174-F1180, 2009.

[34] Ö. Kasimay, E. Güzel, A. Gemici et al., "Colitis-induced oxidative damage of the colon and skeletal muscle is ameliorated by regular exercise in rats: the anxiolytic role of exercise," Experimental Physiology, vol. 91, no. 5, pp. 897-906, 2006.

[35] M. Sasaki, S. Bharwani, P. Jordan et al., "Increased disease activity in eNOS-deficient mice in experimental colitis," Free Radical Biology and Medicine, vol. 35, no. 12, pp. 1679-1687, 2003.

[36] W. Aoi, Y. Naito, T. Takagi et al., "Regular exercise reduces colon tumorigenesis associated with suppression of iNOS," Biochemical and Biophysical Research Communications, vol. 399, no. 1, pp. 14-19, 2010.

[37] N. T. Jenkins, R. Q. Landers, S. J. Prior, N. Soni, E. E. Spangenburg, and J. M. Hagberg, "Effects of acute and chronic endurance exercise on intracellular nitric oxide and superoxide in circulating $\mathrm{CD}_{4} 4^{+}$and $\mathrm{CD} 34^{-}$cells," Journal of Applied Physiology, vol. 111, no. 3, pp. 929-937, 2011.

[38] M. Zwolinska-Wcislo, T. Brzozowski, A. Ptak-Belowska et al., "Nitric oxide-releasing aspirin but not conventional aspirin improves healing of experimental colitis," World Journal of Gastroenterology, vol. 17, no. 36, pp. 4076-4089, 2011.

[39] W. Dou, J. Zhang, A. Sun et al., "Protective effect of naringenin against experimental colitis via suppression of Toll-like receptor 4/NF- $\kappa$ B signalling," The British Journal of Nutrition, vol. 110, no. 4, pp. 599-608, 2013.

[40] J. Xing, C. You, K. Dong et al., "Ameliorative effects of 3,4-oxoisopropylidene-shikimic acid on experimental colitis and their mechanisms in rats," International Immunopharmacology, vol. 15, no. 3, pp. 524-531, 2013.

[41] A. Sonnenberg, "Age distribution of IBD hospitalization," Inflammatory Bowel Diseases, vol. 16, no. 3, pp. 452-457, 2010. 


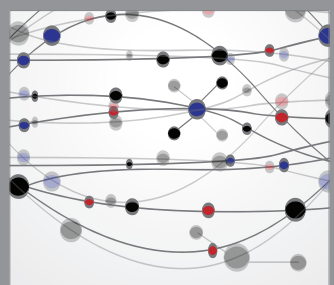

The Scientific World Journal
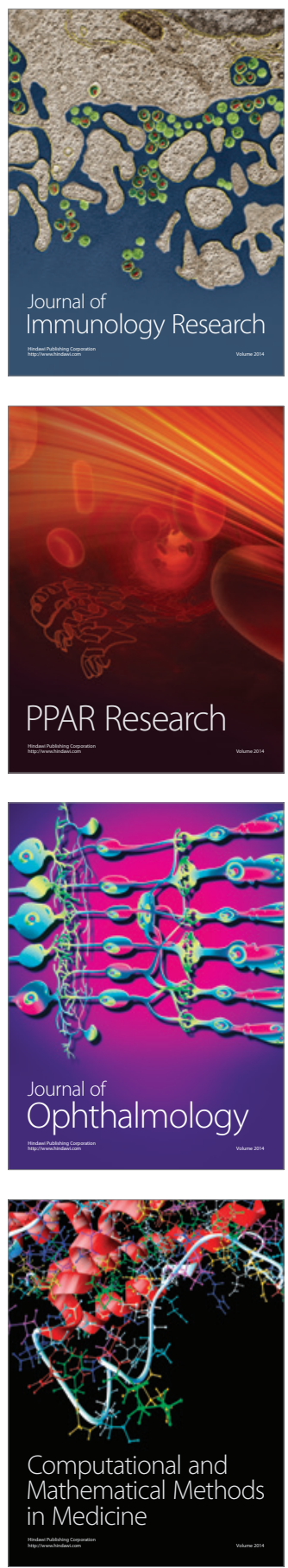

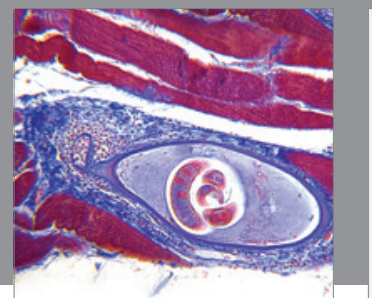

Gastroenterology

Research and Practice
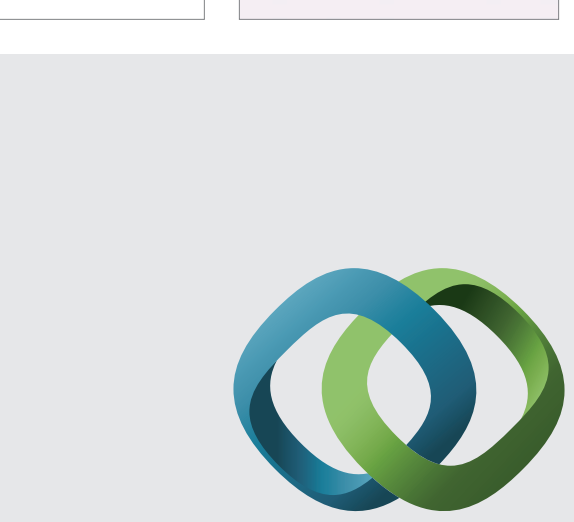

\section{Hindawi}

Submit your manuscripts at

http://www.hindawi.com
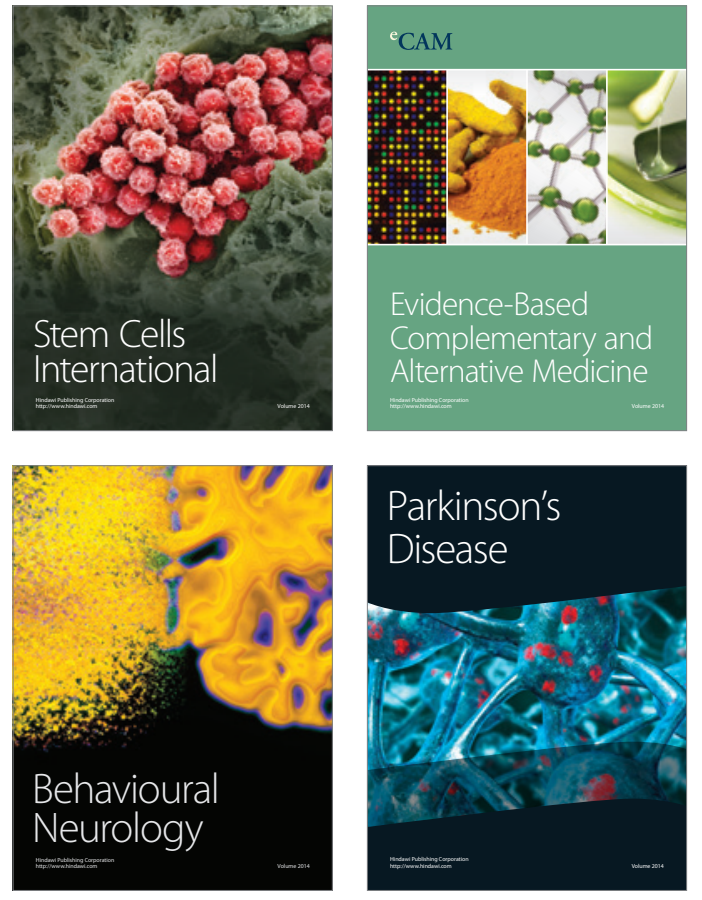
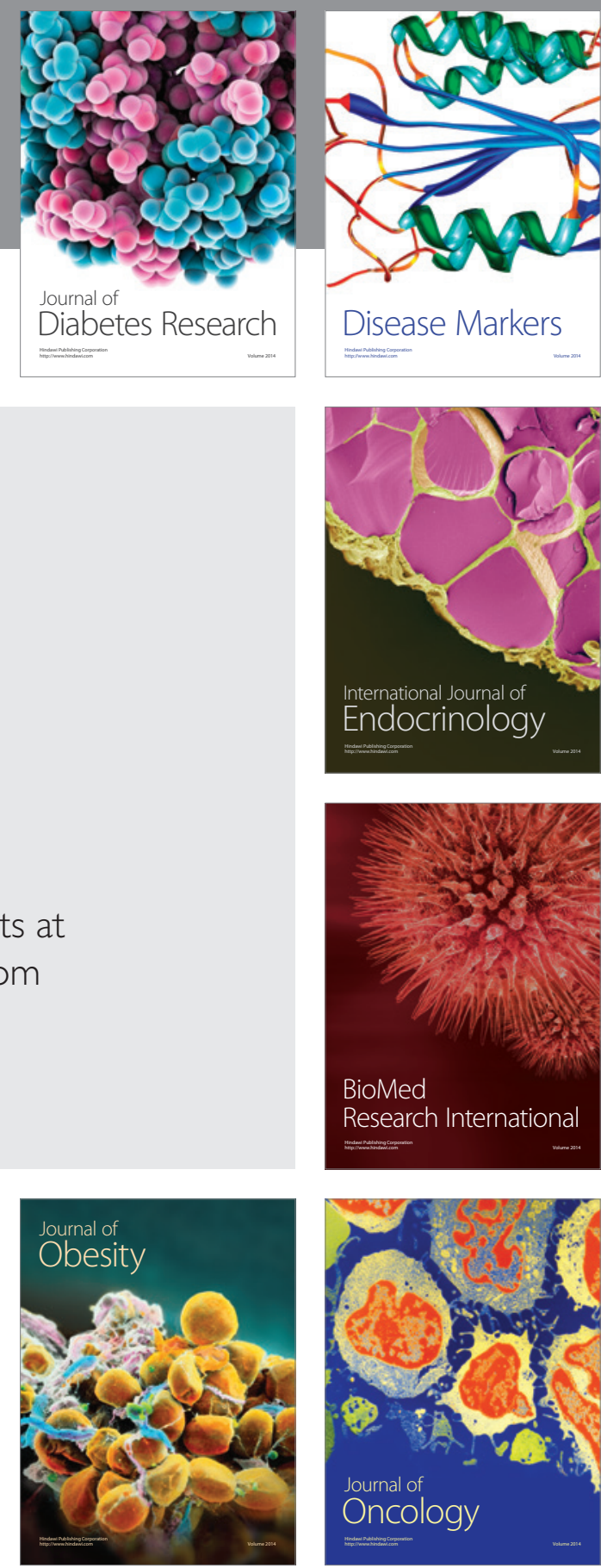

Disease Markers
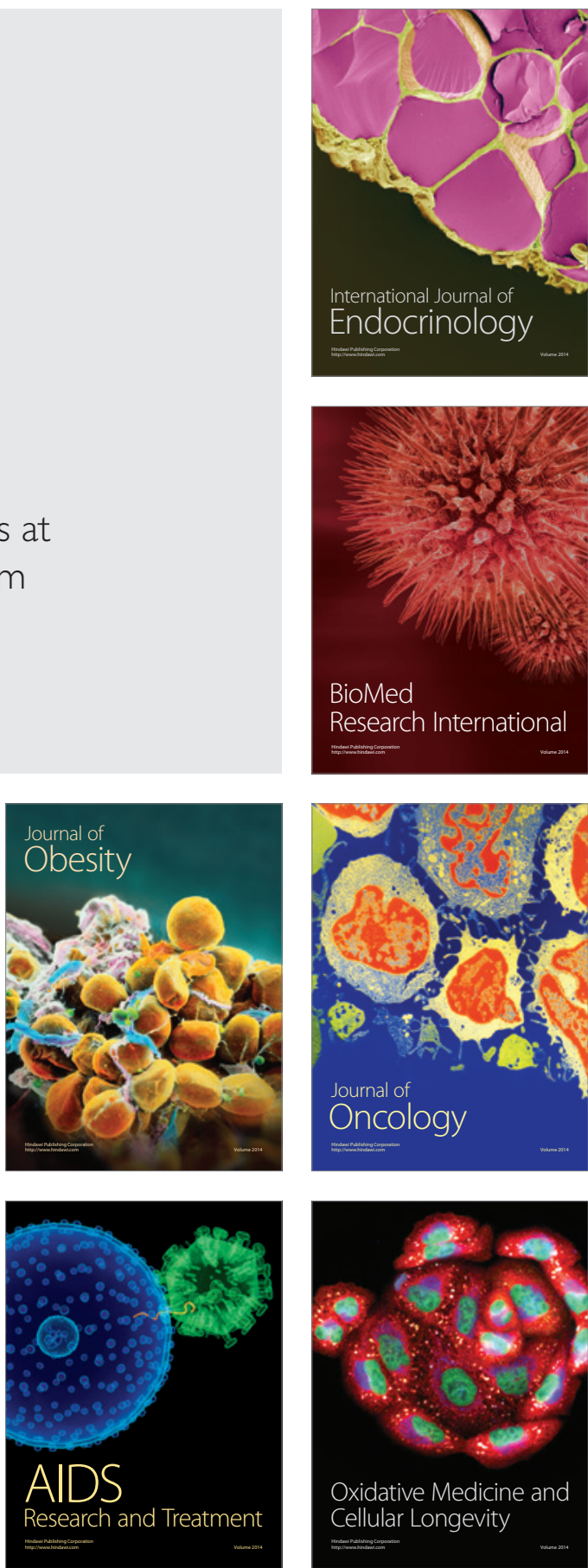